\title{
Four selenoproteins, protein biosynthesis, and Wnt signalling are particularly sensitive to limited selenium intake in mouse colon
}

Citation for published version (APA):

Kipp, A., Banning, A., van Schothorst, E. M., Meplan, C., Schomburg, L., Evelo, C., Coort, S., Gaj, S., Keijer, J., Hesketh, J., \& Brigelius Flohe, R. (2009). Four selenoproteins, protein biosynthesis, and Wnt signalling are particularly sensitive to limited selenium intake in mouse colon. Molecular Nutrition \& Food Research, 53(12), 1561-72. https://doi.org/10.1002/mnfr.200900105

Document status and date:

Published: 01/01/2009

DOI:

10.1002/mnfr.200900105

Document Version:

Publisher's PDF, also known as Version of record

\section{Document license:}

Taverne

Please check the document version of this publication:

- A submitted manuscript is the version of the article upon submission and before peer-review. There can be important differences between the submitted version and the official published version of record.

People interested in the research are advised to contact the author for the final version of the publication, or visit the DOI to the publisher's website.

- The final author version and the galley proof are versions of the publication after peer review.

- The final published version features the final layout of the paper including the volume, issue and page numbers.

Link to publication

\footnotetext{
General rights rights.

- You may freely distribute the URL identifying the publication in the public portal. please follow below link for the End User Agreement:

www.umlib.nl/taverne-license

Take down policy

If you believe that this document breaches copyright please contact us at:

repository@maastrichtuniversity.nl

providing details and we will investigate your claim.
}

Copyright and moral rights for the publications made accessible in the public portal are retained by the authors and/or other copyright owners and it is a condition of accessing publications that users recognise and abide by the legal requirements associated with these

- Users may download and print one copy of any publication from the public portal for the purpose of private study or research.

- You may not further distribute the material or use it for any profit-making activity or commercial gain

If the publication is distributed under the terms of Article $25 \mathrm{fa}$ of the Dutch Copyright Act, indicated by the "Taverne" license above, 


\title{
Four selenoproteins, protein biosynthesis, and Wnt signalling are particularly sensitive to limited selenium intake in mouse colon
}

\author{
Anna Kipp ${ }^{1 *}$, Antje Banning ${ }^{1 *}$, Evert M. van Schothorst ${ }^{2,3}$, Catherine Méplan ${ }^{4}$, \\ Lutz Schomburg ${ }^{5}$, Chris Evelo ${ }^{6}$, Susan Coort ${ }^{6}$, Stan Gaj ${ }^{6}$, Jaap Keijer ${ }^{2}$, John Hesketh ${ }^{4}$ \\ and Regina Brigelius-Flohé ${ }^{1}$ \\ ${ }^{1}$ German Institute of Human Nutrition Potsdam-Rehbruecke, Germany \\ ${ }^{2}$ Human and Animal Physiology, Wageningen University, Wageningen, The Netherlands \\ ${ }^{3}$ RIKILT Institute of Food Safety, Wageningen, The Netherlands \\ ${ }^{4}$ Institute for Cell and Molecular Biosciences, The Medical School, Newcastle University, UK \\ ${ }^{5}$ Charité Universitätsmedizin, Berlin, Germany \\ ${ }^{6}$ Department of Bioinformatics-BiGCaT, University of Maastricht, Maastricht, The Netherlands
}

Selenium is an essential micronutrient. Its recommended daily allowance is not attained by a significant proportion of the population in many countries and its intake has been suggested to affect colorectal carcinogenesis. Therefore, microarrays were used to determine how both selenoprotein and global gene expression patterns in the mouse colon were affected by marginal selenium deficiency comparable to variations in human dietary intakes. Two groups of 12 mice each were fed a selenium-deficient $(0.086 \mathrm{mg} \mathrm{Se} / \mathrm{kg})$ or a selenium-adequate $(0.15 \mathrm{mg} \mathrm{Se} / \mathrm{kg})$ diet. After $6 \mathrm{wk}$, plasma selenium level, liver, and colon glutathione peroxidase (GPx) activity in the deficient group was 12,34 , and $50 \%$, respectively, of that of the adequate group. Differential gene expression was analysed with mouse $44 \mathrm{~K}$ whole genome microarrays. Pathway analysis by GenMAPP identified the protein biosynthesis pathway as most significantly affected, followed by inflammation, Delta-Notch and Wnt pathways. Selected gene expression changes were confirmed by quantitative real-time PCR. GPx1 and the selenoproteins W, H, and M, responded significantly to selenium intake making them candidates as biomarkers for selenium status. Thus, feeding a marginal selenium-deficient diet resulted in distinct changes in global gene expression in the mouse colon. Modulation of cancer-related pathways may contribute to the higher susceptibility to colon carcinogenesis in low selenium status.

\section{Keywords:}

Cancer / Microarrays / Selenium / Selenoproteins / Wnt signalling
Received: March 10, 2009 Revised: April 22, 2009 Accepted: April 26, 2009

\section{Introduction}

The current recommended daily intake for the essential micronutrient selenium ranges between $40 \mu \mathrm{g} /$ day (WHO)

Correspondence: Professor Regina Brigelius-Flohé, Department of Biochemistry of Micronutrients, German Institute of Human Nutrition Potsdam-Rehbruecke, Arthur-Scheunert-Allee 114-116, D-14558 Nuthetal, Germany

E-mail: flohe@dife.de

Fax: +49-33200-88-407

Abbreviations: Dvl, dishevelled; FC, fold change; FDR, False discovery rate; Sec, selenocysteine; $\mathbf{q P C R}$, quantitative real-time PCR

(c) 2009 WILEY-VCH Verlag GmbH \& Co. KGaA, Weinheim and $85 \mu \mathrm{g}$ /day (Australia) for adult males, depending on the country; the value for females is normally $10 \mu \mathrm{g}$ less [1]. These intakes are not achieved in many countries [1] and sub-optimal selenium intake may have impact on immune function and susceptibility to viral disease and cancers [2]. Both observational and intervention studies suggest that a low selenium status is inversely correlated with an increased colorectal cancer incidence [3-5]. Furthermore, results of the Nutritional Prevention of Cancer Trial in USA indicated that a daily supplement of $200 \mu \mathrm{g}$ Se reduced mortality from colorectal cancer [6].

*These authors contributed equally to this work 
Selenium is incorporated into selenoproteins as selenocysteine (Sec). In humans, 25 selenoprotein-encoding genes have been identified, whereas the number is 24 in mice [7]. Selenoprotein levels respond differently to selenium deficiency, a phenomenon called the "hierarchy of selenoproteins". Glutathione peroxidase-1 (GPx1) is considered to rank lowest in this hierarchy, since it rapidly declines upon selenium deprivation and is re-synthesized with considerable delay upon selenium repletion $[8,9]$. Others, such as GPx4, GPx2, deiodinases, or thioredoxin reductases rank high in the hierarchy. In general, the ranking of selenoproteins parallels the stability of the pertinent mRNA. However, the ranking of all selenoproteins is not known so far, mainly due to lack of both systematic feeding experiments and data on the response of all selenoproteins.

Selenium intake also affects expression of non-selenoproteins. Organo-selenium compounds increase the expression of phase II enzymes and pro-apoptotic genes and decrease expression of genes regulating cell growth [10, 11]. In mice, stress response, cell cycle/growth control, and angiogenesis/cell adhesion genes are affected by severe selenium deficiency [12]. Xenobiotic metabolizing enzymes are modulated by selenium deficiency [13] via the activation of Nrf2 and Nrf2-independent pathways [14]. Thus, either supranutritional selenium intake or forms of selenium not usually present in the diet alter the expression of a range of non-selenoprotein genes. In addition, nutritionally relevant amounts of selenium have been shown recently to increase expression of protein biosynthesis genes in lymphocytes of human volunteers [15].

Since selenium intake has been implicated in colon carcinogenesis [6], this study used microarray and quantitative real-time PCR (qPCR) analysis of the mouse colon to identify both selenoproteins and novel targets affected by a selenium depletion comparable to those found in humans. We focussed on the colon because it is one of the organs in which selenium status affects development of cancer [6]. Levels of SelW, GPx1, SelH, and SelM mRNAs were downregulated in selenium deficiency. Non-selenoprotein pathways were also affected, notably those involved in protein biosynthesis, inflammatory pathways, and Wnt signalling, which might contribute to higher cancer risk in selenium deficiency.

\section{Materials and methods}

\subsection{Animals, feeding protocol, and sampling}

The animal study was approved by the Governmental Animal Ethics Committee (MLUV 32-44457+41). Male C57BL/6J mice (3-4 wk of age) from Charles River (Sulzfeld, Germany) were randomly assigned to the selenium-deficient or selenium-adequate group (12 mice per group) with free access to food and water. The selenium-adequate diet was produced by mixing selenomethionine (Acros, Geel, Belgium) into the selenium-deficient diet (No. C1045 with $50 \%$ carbohydrates, $17 \%$ protein, $5 \%$ fat, $4 \%$ fibre, and mixture of micronutrients; Altromin, Lage, Germany) containing $0.086 \mathrm{mg} \mathrm{Se} / \mathrm{kg}$ [16] to yield a selenium content of $0.15 \mathrm{mg} / \mathrm{kg}$ corresponding to the dietary reference intake for mice [17]. Diets were fed as powder for $6 \mathrm{wk}$ until mice were killed in the non-fasted state. Animals were anesthetized with isofluran and blood was withdrawn from the retro-orbital plexus. Anesthetized animals were killed by cervical dislocation. Plasma and tissues freeze clamped in liquid nitrogen were stored at $-80^{\circ} \mathrm{C}$.

\subsection{RNA isolation}

Colon tissue was ground under liquid nitrogen. In total, 20-30 mg powder were suspended in $800 \mu \mathrm{L}$ of cold Trizol (Invitrogen, Karlsruhe, Germany), homogenized with a tissue lyzer (Qiagen, Hilden, Germany), and RNA isolated using the Trizol protocol and RNeasy mini columns (Qiagen). RNA quality was checked using a Bioanalyzer 2100 (Agilent Technologies, Böblingen, Germany). RNA samples subsequently used for microarray analysis had a RIN-number $\geq 9.0$.

\subsection{Microarray analysis}

Differential gene expression was analysed using one RNA sample per mouse 44K microarray (Agilent Technologies) [18]. Briefly, the microarray (G4122A) contains $\sim 41000$ probes that cover all known genes in the mouse genome and the primary resulting transcripts. A total of $500 \mathrm{ng}$ RNA was subjected to cDNA synthesis and subsequent cRNA amplification and labelling, using the Agilent Low RNA Input Fluorescent Linear Amplification Kit. Each cDNA sample was split in two aliquots: one (sample) was labelled with Cyanine 5-CTP (Сy5), the other (reference) with Cyanine 3-CTP (Cy3). Cy5 and Cy3 were obtained from PerkinElmer (Boston, MA, USA). Cy-labelled cRNAs were purified using RNeasy mini columns (Qiagen). A reference pool was generated with equimolar amounts of each Cy3-labelled cRNA. Hybridization of $1 \mu \mathrm{g}$ Cy5-labelled sample cRNA and $1 \mu \mathrm{g}$ of the Cy3-labelled reference pool cRNA and subsequent washing were performed by following the Agilent hybridization procedure with modifications [18]. Microarrays were scanned with a Scanarray Express HT scanner (PerkinElmer) and signal intensity of each spot determined with ArrayVision 8.0 (Imaging Research, Ont., Canada). Per spot signal over background intensity was calculated per array for both channels and each averaged over all arrays; those with a threshold above 2.0 were processed further. Raw data quality of the microarrays was assessed using the software "R" [19] and Microsoft Excel (Microsoft, Redwood, Maryland, MD, USA), based on intensity ratios $(\mathrm{M})$ against the average intensity $(\mathrm{A})$ plots (MA plots), scatter plots, and NP plots (sample size $\mathrm{n}$ times the 
proportion of non-forming items P). All arrays passed. Subsequently, data were normalized [20] using GeneMaths XT 1.6 (Applied Maths, Sint-Martens-Latem, Belgium). False discovery rate (FDR) analysis at a cut-off of $5 \%$ was carried out according to the Benjamini-Hochberg procedure [21]. Significantly, regulated genes were also identified with Student's $t$-test $(p<0.05)$.

\subsection{Pathway analysis}

Probes were annotated to UniProt and Ensembl IDs to make them compatible with the program GenMAPP (Gene Map Annotator and Pathway Profiler) [22] that was used for pathway analysis. Pathways were selected using the MAPPFinder based on the amount of regulated genes present [23]. Genes were considered to be regulated when meeting the criterion: absolute fold change (FC) $\geq 1.2$ and $p$-value $\leq 0.05$. An FC of 1.2 was chosen not to overlook small changes caused by dietary intervention and more importantly to find multiple altered genes in one pathway reflecting its physiological relevance [24]. Per pathway $z$-score was calculated [23].

\section{5 qPCR}

RNA $(3 \mu \mathrm{g})$ was reversely transcribed with $150 \mathrm{fmol}$ oligo(dT) 15 primers and $180 \mathrm{U}$ moloney murine leukemia virus reverse transcriptase (Promega, Mannheim, Germany) in a total volume of $45 \mu \mathrm{L}$. qPCRs (Mx3005P ${ }^{\mathrm{TM}}$ qPCR System, Stratagene, Amsterdam, Netherlands) were performed in triplicates with $1 \mu \mathrm{L}$ of tenfold diluted cDNA in $25 \mu \mathrm{L}$ reaction mixtures using SYBR Green I (Molecular Probes, Eugene, OR, USA) as fluorescent reporter. PCR products were quantified with a standard curve. Primers (Table 1) were designed to be specific for cDNA with PerlPrimer v1.1.14 [25]. Hprt and Rpl13a were used as reference genes based on criteria: least variation in microarray data between all samples (\%CV <5\%), mean expression level ratio of deficient over adequate group close to 1 , and an expression level of at least ten times the background. The mean of reference genes was used for normalization [26].

\subsection{PCR arrays}

Mouse Wnt Signaling Pathway $\mathrm{RT}^{2}$ Profiler $^{\mathrm{TM}}$ PCR Arrays and $\mathrm{RT}^{2}$ Real-Timer SyBR Green/ROX qPCR Master Mix were purchased from SuperArray Bioscience (Frederick, MD, USA). cDNA of the selenium-deficient and -adequate group was pooled to equal amounts to provide two samples for PCR array analysis. Raw data of 84 analyzed genes were normalized and analysed by the $\mathrm{RT}^{2}$ Profiler ${ }^{\mathrm{TM}}$ PCR Array Data Analysis Web Portal using the $\Delta \Delta \mathrm{Ct}$ method.

\subsection{Liver GPx activity and plasma selenium content}

In total, $20 \mathrm{mg}$ of tissue powder were homogenized in $500 \mu \mathrm{L}$ $100 \mathrm{mM}$ Tris $/ \mathrm{HCl}, 300 \mathrm{mM} \mathrm{KCl,} \mathrm{0.1 \%} \mathrm{Triton} \mathrm{X-100,} \mathrm{pH} \mathrm{7.6,}$ containing $4 \mu \mathrm{L}$ of protease inhibitor cocktail (Calbiochem, Bad Soden, Germany). Cellular debris was removed at $20000 \times \mathrm{g}, \quad 15 \mathrm{~min}, 4^{\circ} \mathrm{C}$. Protein content was estimated according to Bradford [27]. GPx activity was measured in the glutathione reductase-coupled test optimized for mouse tissue [28] and expressed as $\mathrm{mU} / \mathrm{mg}$ protein. The amount of plasma selenium was measured fluorimetrically as described [29] and modified previously [30].

\subsection{Statistics}

Student's $t$-test was used to compare differences between group (12 animals each) means. $p<0.05$ was considered significant. Statistical analysis was performed using GraphPad Prism version 5 (La Jolla, San Diego, CA, USA).

\section{Results}

\subsection{Plasma selenium concentration and liver GPx activity}

Plasma selenium in mice fed the selenium-deficient diet was significantly lower than in those on selenium-adequate diet (Fig. 1A) indicating the success of the feeding. The plasma concentrations observed here were consistent with the previous study [16]. GPx activity, a classical functional marker of Se status, was about one-third of the adequate group in the liver and half in the colon of Se-deficient mice (Figs. 1B and C, respectively). Maximal differences between feeding groups were usually reached after $5 \mathrm{wk}$ and did not further change after $6 \mathrm{wk}$. Food intake, weight gain, and behaviour were unaffected by the diets with different selenium contents. Histological monitoring of the colons did not show any changes in cell pattern in selenium deficiency. Especially, no infiltration of inflammatory cells was observed (data not shown). Thus, any change in gene expression described in the following does not result from a change in composition of colon cells.

\subsection{Selenium-responsive genes}

Colon RNA samples from 12 selenium-deficient and 12 selenium-adequate mice individually hybridized to whole genome microarrays yielded a total of 21008 transcripts (13656 unique and annotated genes) with levels twice above background and were used for subsequent data analyses. Mean gene expression ratios of selenium-deficient and selenium-adequate samples were calculated. By using an FDR $\leq 5 \%$ a total of 952 genes (722 down- and 230 up-regulated in 
Table 1. Primer sequences $\left(5^{\prime} \rightarrow 3^{\prime}\right)$

\begin{tabular}{|c|c|c|c|}
\hline Gene & Acc. Number & Primer sequence & Product size $(b p)$ \\
\hline 14-3-3 (Ywhaq) & NM_011739 & $\begin{array}{l}\text { fwd CACGGTCCTGGAATTGTTGG } \\
\text { rev ATCGCCACAAGCTACTTCAGC }\end{array}$ & 125 \\
\hline$\beta$-Catenin & NM_007614.2 & $\begin{array}{l}\text { fwd AGCTGGCCTGGTTTGATACTGAC } \\
\text { rev CTAAAACCATTCCCACCCTACCAA }\end{array}$ & 130 \\
\hline c-Myс & NM_010849.4 & $\begin{array}{l}\text { fwd AATCCTGTACCTCGTCCGATTCC } \\
\text { rev TCTTGCTCTTCTTCAGAGTCGCT }\end{array}$ & 150 \\
\hline Dio 1 & NM_007860 & $\begin{array}{l}\text { fwd GGGATTTCATTCAAGGCAGCAGG } \\
\text { rev TGTGGAGGCAAAGTCATCTACGA }\end{array}$ & 115 \\
\hline Dvl2 & NM_007888.3 & $\begin{array}{l}\text { fwd GGTTGTCTCCTGGCTTGTGTC } \\
\text { rev CCCAATTCCACTGGTCCTTTCTG }\end{array}$ & 135 \\
\hline GPx1 & NM_008160 & $\begin{array}{l}\text { fwd GAAGAGATTCTGAATTCCCTCAA } \\
\text { rev CACACCAGGAGAATGGCAAGA }\end{array}$ & 256 \\
\hline GPx2 & NM_030677 & $\begin{array}{l}\text { fwd GTGCTGATTGAGAATGTGGC } \\
\text { rev AGGATGCTCGTTCTGCCCA }\end{array}$ & 252 \\
\hline GPx3 & NM_001083929 & $\begin{array}{l}\text { fwd CCATTTGGCTTGGTCATTCTGGG } \\
\text { rev CACCTGGTCGAACATACTTGAGAC }\end{array}$ & 105 \\
\hline GPx4 & NM_001037741 & $\begin{array}{l}\text { fwd GCTGGGAAATGCCATCAAATGGA } \\
\text { rev ACGGCAGGTCCTTCTCTATCAC }\end{array}$ & 115 \\
\hline Gsk3 $\beta$ & NM_19827 & $\begin{array}{l}\text { fwd ATCAGCTGTTCAGAAGTCTAGCCT } \\
\text { rev AGCTGCTTTGCACTTCCAAAGTC }\end{array}$ & 132 \\
\hline Hmox1 (heme oxygenase-1) & NM_010442.1 & $\begin{array}{l}\text { fwd CCTGGTGCAAGATACTGCCC } \\
\text { rev GAAGCTGAGAGTGAGGACCCA }\end{array}$ & 105 \\
\hline Lef1 & NM_010703.3 & $\begin{array}{l}\text { fwd CCGAGATCAGTCATCCCGAAGAG } \\
\text { rev TTGTCTGACCACCTCATGCCC }\end{array}$ & 109 \\
\hline Nqo1 & NM_008706.4 & $\begin{array}{l}\text { fwd ATGTACGACAACGGTCCTTTCCAG } \\
\text { rev GATGCCACTCTGAATCGGCCA }\end{array}$ & 134 \\
\hline Selenoprotein $\mathrm{H}$ & NM_001037279 & $\begin{array}{l}\text { fwd CCTTATTCCACCAACGCGCCA } \\
\text { rev GCGTCAGCTCGTACAATGCTC }\end{array}$ & 154 \\
\hline Selenoprotein I & NM_027652 & $\begin{array}{l}\text { fwd ACTGGTTACTGCTTCCTCTCCTC } \\
\text { rev CTGCTTCACCACTTGTACGCC }\end{array}$ & 145 \\
\hline Selenoprotein $\mathrm{K}$ & NM_019979 & $\begin{array}{l}\text { fwd ATGGAAGAGGGCCACCAGGA } \\
\text { rev TTACCTTCCTCATCCACCAGCC }\end{array}$ & 100 \\
\hline Selenoprotein M & NM_053267 & $\begin{array}{l}\text { fwd GGACATTCAACTGTACCACAACCT } \\
\text { rev TAGAAGCCGAGCTCCTGTACCA }\end{array}$ & 158 \\
\hline Selenoprotein $\mathrm{O}$ & NM_027905 & $\begin{array}{l}\text { fwd TGACACTGAGTTCCAAAGGCAC } \\
\text { rev GTTAGTGAAGTCAGCACCAGTCAG }\end{array}$ & 138 \\
\hline Selenoprotein P & NM_001042613 & $\begin{array}{l}\text { fwd CTCATCTATGACAGATGTGGCCGT } \\
\text { rev AAGACTCGTGAGATTGCAGTTTCC }\end{array}$ & 137 \\
\hline Selenoprotein S & NM_024439.3 & $\begin{array}{l}\text { fwd GAAGGCCTCAGGAAGAAGATGGT } \\
\text { rev GTCTCCAGGAGCAGGTTCCA }\end{array}$ & 137 \\
\hline Selenoprotein T & NM_001040396 & $\begin{array}{l}\text { fwd CTTTAAATGATGTGCCAGTGTGGT } \\
\text { rev GGTAGGGCTATGATCGATGATGTG }\end{array}$ & 140 \\
\hline Selenoprotein W & NM_009156 & $\begin{array}{l}\text { fwd ATGCCTGGACATTTGTGGGGA } \\
\text { rev GCAGCTTTGATGGCGGTCAC }\end{array}$ & 152 \\
\hline Selenoprotein X & NM_013759 & $\begin{array}{l}\text { fwd ACTTCGAGCCAGGTGTCTACG } \\
\text { rev GGCACTTGGTCACACTGTCTG }\end{array}$ & 129 \\
\hline Sep15 & NM_053102 & $\begin{array}{l}\text { fwd GTTTCAAGCGGCGTCTGCTC } \\
\text { rev TGCTTCTTCCTGACAGCACCC }\end{array}$ & 159 \\
\hline Sephs2 & NM_009266.3 & $\begin{array}{l}\text { fwd CAAGTACGGAGAGGGTCACCA } \\
\text { rev CGTTGGAATTATCAGGAGCAGCAG }\end{array}$ & 148 \\
\hline Smad4 & NM_008540 & $\begin{array}{l}\text { fwd CACACCTAATTTGCCTCACCACC } \\
\text { rev ACTCAGGAGCAGGATGATTGGA }\end{array}$ & 136 \\
\hline Stat3 & NM_213659 & $\begin{array}{l}\text { fwd AAAGGACATCAGTGGCAAGACCC } \\
\text { rev TCGCATCCATGATCTTATAGCCCA }\end{array}$ & 112 \\
\hline Tle2 & NM_019725.1 & $\begin{array}{l}\text { fwd CTGGATTGCCTGAACCGAGAC } \\
\text { rev CTCTGCTTTGATCCGTGGTGTG }\end{array}$ & 137 \\
\hline Trspap1 & NM_027925.3 & $\begin{array}{l}\text { fwd AGCACCATGCAGACATATGAAGAG } \\
\text { rev GTGACAGTCCATCAGAGCATCGT }\end{array}$ & 134 \\
\hline Txnrd 1 & NM_015762.1 & $\begin{array}{l}\text { fwd TACTGCATCAGCAGTGATGATC } \\
\text { rev CCATGTTCTTCCATGTGTTCAC }\end{array}$ & 206 \\
\hline
\end{tabular}


Table 1. Continued

\begin{tabular}{|c|c|c|c|}
\hline Gene & Acc. Number & Primer sequence & Product size (bp) \\
\hline Txnrd 2 & NM_013711.3 & $\begin{array}{l}\text { fwd TACAGCAATGTTCCCACAACTGTC } \\
\text { rev CTATCCGCCACCGTGAACTC }\end{array}$ & 148 \\
\hline Txnrd 3 & NM_153162.3 & $\begin{array}{l}\text { fwd TCGACAACGAACGTGTGGTGG } \\
\text { rev AGTAGCTGCTTCGTGAGCCC }\end{array}$ & 111 \\
\hline Reference genes & & & \\
\hline $\begin{array}{l}\text { Hypoxanthine phosphoribosyl } \\
\text { transferase (Hprt1) }\end{array}$ & NM_013556 & $\begin{array}{l}\text { fwd GCAGTCCCAGCGTCGTG } \\
\text { rev GGCCTCCСАTСТCСTTCAT }\end{array}$ & 168 \\
\hline Ribosomal protein L13a (Rpl13a) & NM_009438 & $\begin{array}{l}\text { fwd GTTCGGCTGAAGCCTACCAG } \\
\text { rev TTCCGTAACCTCAAGATCTGCT }\end{array}$ & 157 \\
\hline
\end{tabular}
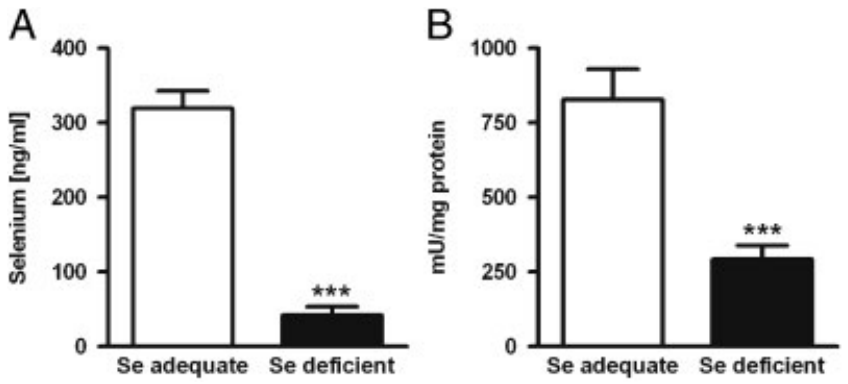

selenium deficiency) were identified. Using a less stringent criterium, $p$-value of $\leq 0.05,3995$ genes (1979 down- and 2016 up-regulated in selenium deficiency) were identified. This number clearly exceeds the number you might expect by chance ( $5 \%$ would be 1050 genes).

A complete list of 20 selenoprotein genes being expressed in the mouse colon is given in Table 2. Four selenoprotein genes were significantly lower expressed in selenium-deficient mice: Selw, Gpx1, Selh, and Selm. The remaining four known murine selenoprotein genes Dio2, Dio3, Seln, and Selv were not expressed at detectable levels in any dietary group.

To confirm the array data, qPCR was performed for all selenoprotein genes (Table 2). Significantly, lower expression after the marginal selenium-deficient diet was confirmed for Selw, Gpx1, Selh, and Selm. Expression of Gpx3, Selk, Sels, Txnrd1, Sep15, and Selt significantly responded to selenium supply, which was not obvious from the array data. Similarly, a small increase in the expression of Txnrd2 and Txnrd3 was observed in qPCR but not in arrays. qPCR showed expression levels of Gpx2, Sephs2, Sepp1, Seli, Dio1, Sepx1, Selo, and Gpx4 to be unaffected by Se intake, as observed in microarrays. Thus, qPCR confirmed the major changes observed by microarray analysis. The gene for tRNA Sec-associated protein 1 (Trspap1, also known as Secp43), a factor required for selenoprotein synthesis [31], was slightly, but significantly, decreased in Se-deficient mice according to microarrays (FC: 0.84; $p$-value: 0.017 ) and qPCR (Fig. 2A).

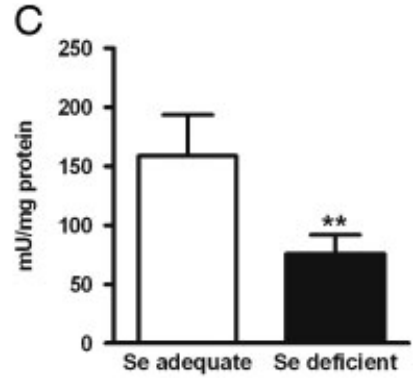

Figure 1. Plasma selenium concentration (A), liver (B), and colon (C) GPx activity in selenium-deficient and selenium-adequate mice. Values are means of 12 animals per group (five animals in case of colon) measured in triplicate \pm SD. $* * p<0.01$ and ${ }^{* * *} p<0.001$ using Student's $t$-test.

\subsection{Selenium-responsive pathways}

Pathways were analyzed using GenMAPP. The data set consisted of 41441 probes of which 28208 were annotated to UniProt- and Ensembl-IDs. In total, 6536 genes of these 28208 probes were linked to murine pathways present in GenMAPP (Table 3). A total of 2294 genes were regulated according to the criteria: absolute $\mathrm{FC} \geq 1.2$ and $p$-value $\leq 0.05$. Based on these regulated genes and the total amount of 6536 genes, pathways influenced by selenium intake were ranked by the $z$-score (see Section 2). Five of the top 15 pathways (translation factors, mRNA processing/ binding, mTOR signalling pathway, regulation of eIF4eand-p70-S6-Kinase, ribosomal proteins) are related to protein biosynthesis (Table 3). A complete list of genes regulated in protein biosynthesis pathways is provided in Supporting Information Table S1.

The remaining ten regulated pathways comprised stress response and regulatory phenomena, in particular related to inflammation (TNF $\alpha-N F \kappa B$, IL-2, IL-3) and carcinogenesis (Alpha6-Beta4-Integrin, Delta-Notch). These pathways contained one or more of the genes for Smad4, Stat3, Ywhaq (tyrosine 3-monooxygenase/tryptophan 5-monooxygenase activation protein $\theta$, also called 14-3-3 $\theta$ ), and glycogen synthase kinase $3 \beta$ (GSK3 $\beta$ ). Due to their multiple appearances, these genes were selected for and confirmed by qPCR (Figs. 2B-D and Fig. 3B). 


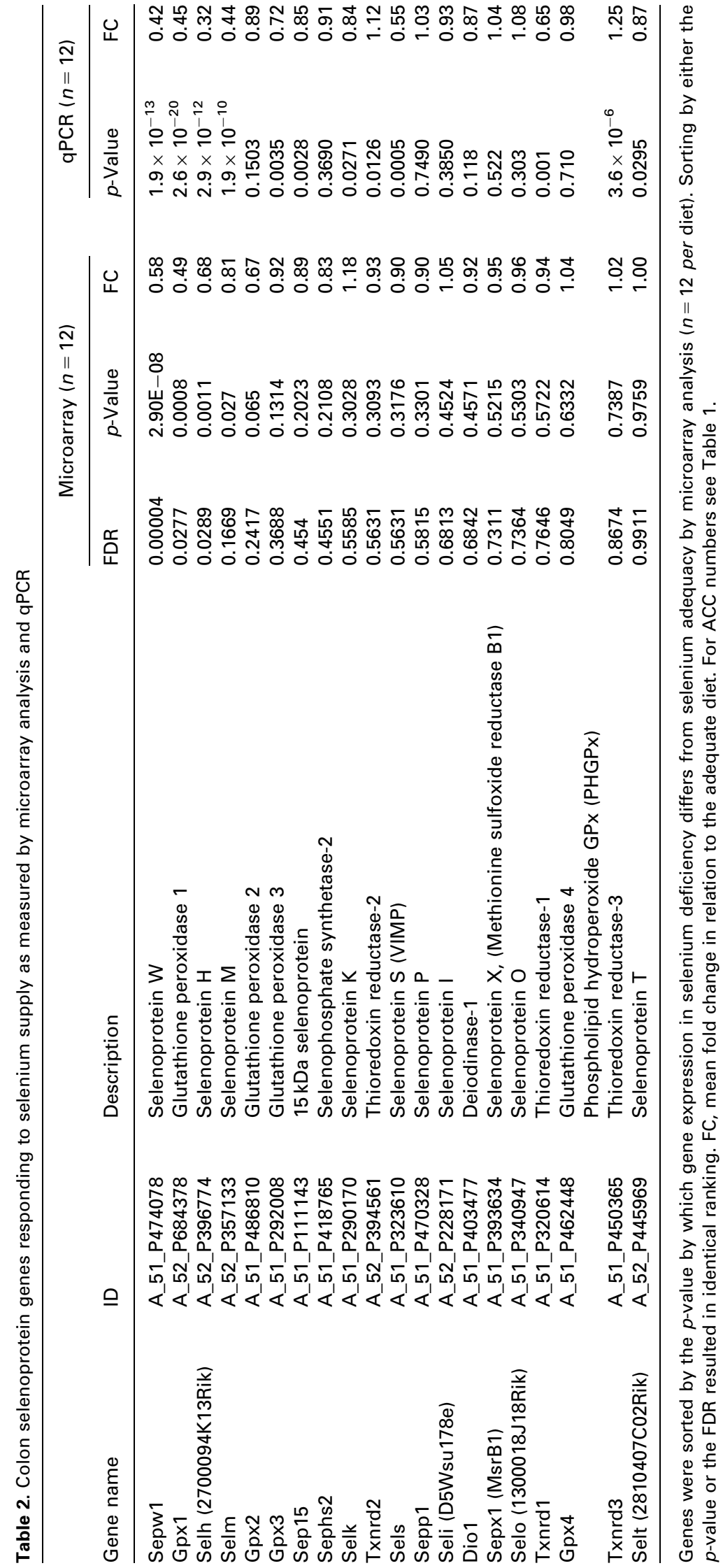



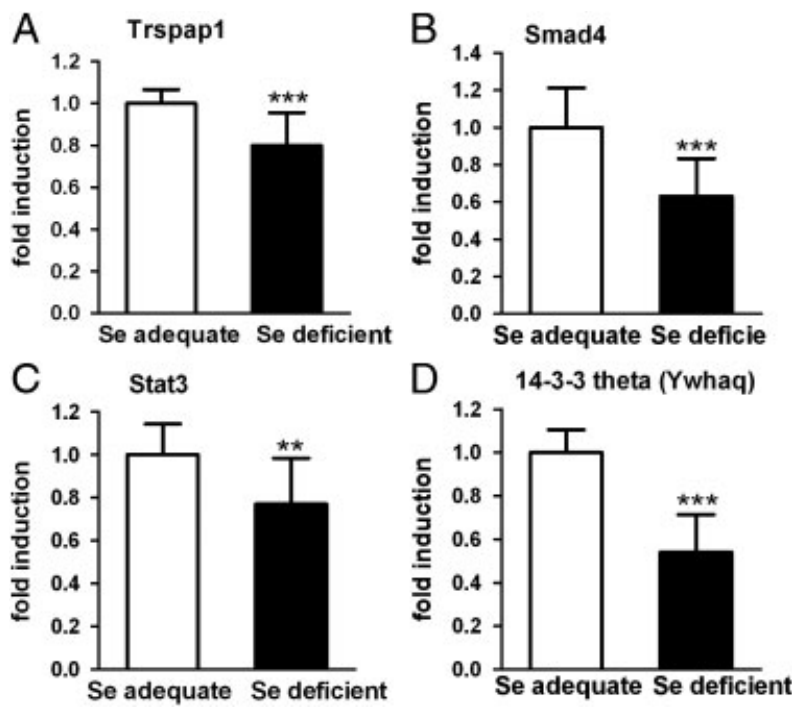

Figure 2. mRNA expression of non-selenoproteins in the colon of selenium-deficient relative to selenium-adequate mice. (A) tRNA Sec-associated protein (Trspap or Secp43), (B) Smad4, and (C) Stat3, (D) 14-3-3 $\theta$ (Ywhaq). Gene expression was analysed in triplicate by qPCR and normalized to the mean of the reference genes Hprt1 and Rpl13a. Values are means of 12 animals per group \pm SD. ${ }^{* *} p<0.01$ and ${ }^{* * *} p<0.001$ using Student's $t$-test. classified as "not expressed" in the arrays and therefore this pathway was further analysed by comparing two pools of samples in a Wnt PCR array. In total, 37 genes responded to lowering the selenium status with an absolute $F C \geq 1.2$, however, only 25 were expressed at a level that could be measured with sufficient sensitivity $\left(c_{\mathrm{T}}\right.$-value $<30$, Table 4$)$. Seven of these 25 genes were also significantly regulated when analysed in microarrays (microarray FC and $p$-value, Table 4). In total, 18 genes were "not expressed" in the microarray from which six are still in the table due to a distinct response in the PCR array. Changes in the expression of genes for $\beta$-catenin, GSK3$\beta$, dishevelled (Dvl), lymphocyte enhancer factor-1 (Lef1), transducin-like enhancer of split-2 (Tle2), and c-Myc as target of $\beta$-catenin were confirmed by qPCR (Fig. 3A-F).

\section{Discussion}

The aim of this study was to analyse not only the expression of selenoprotein genes but also the global expression patterns in the colon, an organ that responds to the availability of selenium. In contrast to most earlier studies relating gene expression to selenium status, animals were

Table 3. Pathways in which genes were regulated by selenium supply ranked by z-score

\begin{tabular}{|c|c|c|c|}
\hline MAPP Name & Down & Up & z-score \\
\hline Mm_Translation_Factors ${ }^{a)}$ & 86 & 55 & 8.63 \\
\hline Mm_mRNA_processing_binding ${ }^{\text {b) }}$ & 217 & 104 & 8.23 \\
\hline Mm_mTOR-Signaling-Pathwayc) & 55 & 44 & 8.23 \\
\hline Mm_TNF- $\alpha-N F-\kappa B^{d)}$ & 165 & 88 & 8.06 \\
\hline Mm_Regulation-of-elF4e-and-p70-S6-Kinase ${ }^{c)}$ & 56 & 39 & 7.95 \\
\hline Mm_Ribosomal_Proteins & 6 & 27 & 7.15 \\
\hline Mm_Proteasome_Degradation ${ }^{\text {a) }}$ & 98 & 49 & 7.09 \\
\hline Mm_ADP-Ribosylation-Factor ${ }^{\mathrm{c})}$ & 53 & 22 & 7.09 \\
\hline Mm_Gene-Expression ${ }^{\mathrm{b})}$ & 78 & 58 & 7.02 \\
\hline Mm_Phosphoinositides-and-their-downstream-targets ${ }^{\mathrm{c})}$ & 51 & 22 & 6.47 \\
\hline $\mathrm{Mm} \_$IL-2 ${ }^{\mathrm{d})}$ & 68 & 36 & 6.36 \\
\hline Mm_IL-3 ${ }^{\text {d) }}$ & 80 & 38 & 6.26 \\
\hline Mm_Insulin_Signaling a) & 91 & 34 & 6.23 \\
\hline Mm_a6- $\beta 4-I n t e g r i n^{d)}$ & 61 & 34 & 6.22 \\
\hline Mm_Delta-Notch ${ }^{d)}$ & 93 & 23 & 6.19 \\
\hline Mm_WNT-Signaling-Pathwayc) & 73 & 13 & 4.37 \\
\hline Mm_Wnt ${ }^{\mathrm{d})}$ & 105 & 28 & 4.02 \\
\hline
\end{tabular}

Up and down indicate the number of genes which are up- or down-regulated in the respective pathway by selenium deficiency. Underlying database present in GeneMAPP: the break between the Delta-Notch and the Wnt pathway indicates that Wnt does not directly follow Notch.

a) COREG.

b) Reactome.

c) Biocarta.

d) Netpath.

Although the Wnt pathway was not within the top 15 pathways, it also showed a reasonably high $z$-score. However, a high number of genes in the Wnt pathway were fed a selenium-adequate and a marginally deficient diet, the latter containing about half of the selenium considered to be adequate for mice $[17,32]$. The selenium intake, thus, 

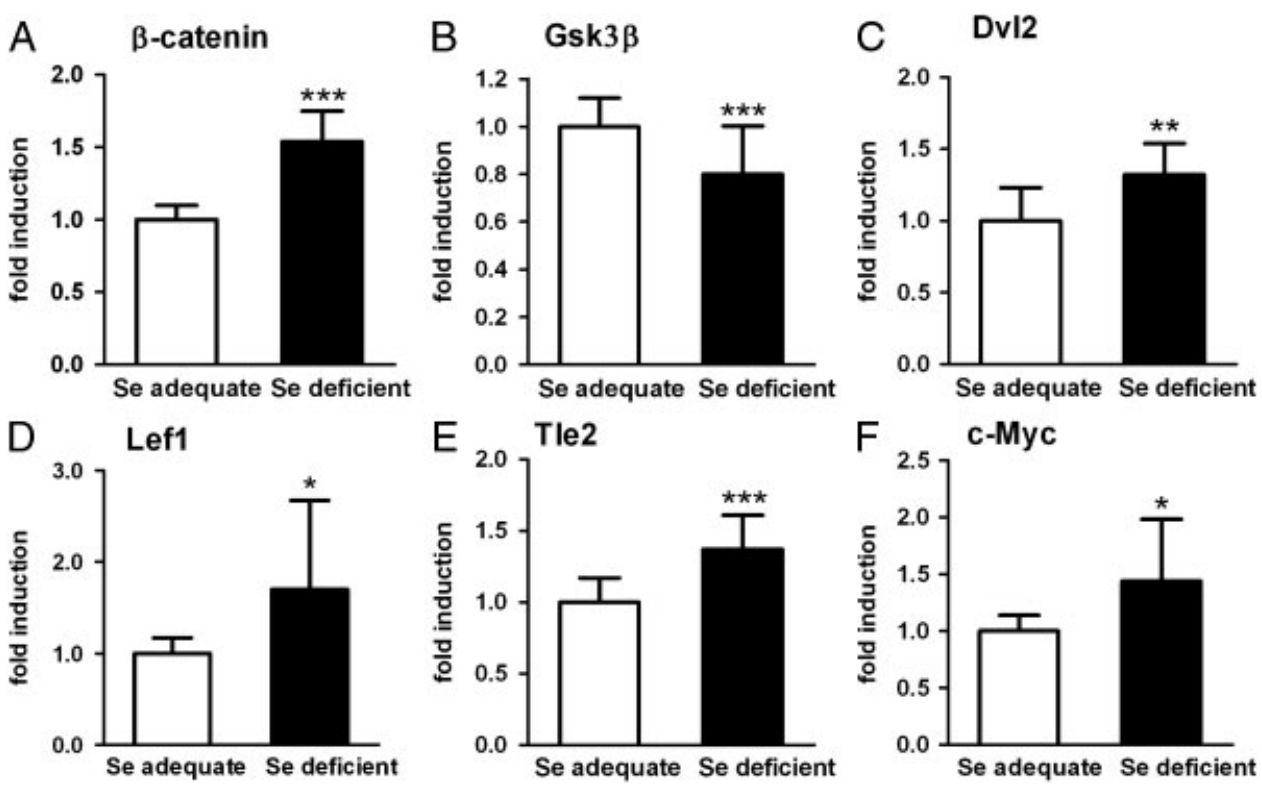

Figure 3. mRNA expression of non-selenoproteins involved in the Wnt pathway in the colon of selenium-deficient relative to selenium-adequate mice. (A) $\beta$-catenin, (B) glycogen synthase kinase $3 \beta$ (Gsk3 $\beta$ ), (C) Dvl2, (D) lymphocyte-enhancing factor-1 (Lef1), (E) transducin-like enhancer of split 2 (Tle2), and (F) c-Myc. Gene expression was analysed in triplicate by QPCR and normalized to the mean of the reference genes Hprt1 and Rpl13a. Values are means of 12 animals per group \pm SD. $\quad{ }^{*} p<0.05$; ** $p<0.01 ;$ and $* * * p<0.001$ using Student's $t$-test.

Table 4. Genes of the Wnt pathway changed in the colon of Se-deficient mice as identified in the microarray and/or the PCR array

\begin{tabular}{|c|c|c|c|c|c|}
\hline Gene name & Agilent ID & Description & Acc. number & $\begin{array}{l}\text { Microarray FC } \\
\text { and ( } p \text {-value) }\end{array}$ & PCR array FC \\
\hline Ctnnb1 & A_51_P272046 & Catenin (cadherin associated protein), $\beta 1$ & NM_007614 & $0.84(0.119)$ & 1.28 \\
\hline Dixdc1 & A_51_P468876 & DIX domain containing 1 & NM_178118 & $1.21(0.011)$ & 1.38 \\
\hline Dvl1 & A_52_P234958 & Dishevelled, dsh homolog 1 (Drosophila) & NM_010091 & $1.12(0.173)$ & 1.32 \\
\hline Dvl2 & A_51_P113106 & Dishevelled 2, dsh homolog (Drosophila) & NM_007888 & n.d. & 1.96 \\
\hline Ep300 & A_52_P411601 & E1A binding protein $\mathrm{p} 300$ & NM_177821 & $0.98(0.712)$ & 1.30 \\
\hline Fbxw11 & A_51_P141860 & F-box and WD-40 domain protein 11 & NM_134015 & $1.42(0.038)$ & 1.33 \\
\hline Fzd1 & A_52_P597634 & Frizzled homolog 1 (Drosophila) & NM_021457 & $1.03(0.751)$ & 1.73 \\
\hline Fzd3 & A_51_P190863 & Frizzled homolog 3 (Drosophila) & NM_021458 & $1.27(0.148)$ & 1.42 \\
\hline Fzd8 & A_51P312517 & Frizzled homolog 8 (Drosophila) & NM_008058 & n.d. & 1.45 \\
\hline Gsk3b & A_52_P641629 & Glycogen synthase kinase $3 \beta$ & NM_019827 & $0.75\left(5,4 \times 10^{-5}\right)$ & 1.06 \\
\hline Lef1 & A_51_P420400 & Lymphoid enhancer binding factor 1 & NM_010703 & n.d. & 5.74 \\
\hline Lrp6 & A_51_P169401 & Low density lipoprotein receptor-related protein 6 & NM_008514 & n.d. & 1.35 \\
\hline Myc & A_52_P278549 & Myelocytomatosis oncogene & NM_010849 & $1.07(0.267)$ & 1.20 \\
\hline Nxn & A_52_P57013 & Nucleoredoxin & NM_008750 & $1.20(0.018)$ & 1.14 \\
\hline Pitx2 & A_52_P57013 & Paired-like homeodomain transcription factor 2 & NM_011098 & $1.31(0.152)$ & 1.68 \\
\hline Rhou & A_51_P227392 & Ras homolog gene family, member $U$ & NM_133955 & $1.12(0.154)$ & 1.36 \\
\hline Senp2 & A_51_P492141 & SUMO/sentrin specific peptidase 2 & NM_029457 & $0.87(0.015)$ & 1.31 \\
\hline Sfrp2 & A_51_P520849 & Secreted frizzled-related protein 2 & NM_009144 & $1.10(0.163)$ & 1.32 \\
\hline Sfrp4 & A_51_P457196 & Secreted frizzled-related protein 4 & NM_016687 & n.d. & 0.59 \\
\hline Tle2 & A_51_P175303 & Transducin-like enhancer of split 2 & NM_019725 & $1.13(0.032)$ & 0.30 \\
\hline Wif1 & A_51_P484526 & Wnt inhibitory factor 1 & NM_011915 & $1.08(0.180)$ & 0.76 \\
\hline Wisp1 & A_51_P220343 & WNT1 inducible signaling pathway protein 1 & NM_018865 & $1.21(0.005)$ & 1.37 \\
\hline Wnt4 & A_51_P130475 & Wingless-related MMTV integration site 4 & NM_009523 & n.d. & 0.65 \\
\hline Wnt5b & A_51_P137991 & Wingless-related MMTV integration site 5B & NM_009525 & $1.02(0.648)$ & 0.67 \\
\hline Wnt6 & A 52 P415155 & Wingless-related MMTV integration site 6 & NM 009526 & $0.91(0.063)$ & 0.28 \\
\hline
\end{tabular}

Genes are sorted based on gene name. The PCR array was performed once. Gene names in bold indicate significant change as measured by qPCR (see Fig. 3).

reflects situations attained by common variation in the human diet. The selenium status reached after $6 \mathrm{wk}$ feeding of these diets is characterized by a drop of plasma selenium to $12 \%$, and liver and colon GPx activity to 34 and $50 \%$, respectively. The decrease, thus, corresponds to a real deficiency and is more severe than expected. Whether a constant reduction in the intake of selenium leads to the same deficiency in humans is not known. Definitely plasma selenium 
levels in Europeans are not as low as $12 \%$ of those in the US. Consequences of a low intake, however, are obvious from the well-known increase in cancer incidence in seleniumdeficient areas [33] and the decrease in cancer incidence by selenium supplementation only in groups entering respective studies with a low selenium status [34].

Transcripts of SelW, GPx1, SelH, and SelM responded significantly to selenium as measured by both microarray analysis and qPCR. Although the response of GPx1 was expected, the in vivo response of the other genes had so far been poorly (SelW) or not at all documented (SelH and SelM). The observed fall in SelW expression is consistent with the previously observed almost complete loss in SelW RNA expression in the colon of severely selenium-deficient rats [35] fed a diet containing $1 / 10$ of the Se content in the deficient diet fed in this study. Moreover, SelW mRNA expression strongly decreased in brain and testes of SelP knockout mice [36] and increased in skeletal muscle of rats fed selenium in a range from 0 to $4 \mathrm{mg} / \mathrm{kg}$ diet [37]. Taken together, these data confirm the high sensitivity of SelW to selenium status. Additionally, we show here that expression of SelH, and SelM in the murine colon was also highly sensitive and this novel observation deserves further evaluation, especially in view of their largely unknown functions.

As selenoprotein expression is regulated both at a translational level and at the level of RNA stability [8, 38-40], thus assessment of selenoprotein RNA levels in response to changes in selenium supply provides information on RNA degradation and on the hierarchy of selenoproteins. To date, the mechanisms behind the hierarchical response of all selenoproteins to dietary selenium remain unclear. The tRNA $^{\text {[ser]sec }}$ plays a key role in this process. It is modified post-transcriptionally at two bases and one ribose moiety in the anticodon loop: A37 is modified to $N^{6}$-isopentenyladenosine $\left(i^{6} \mathrm{~A}\right)$, U34 is methylated to methylcarboxyl $-5^{\prime}$ methyluridine $\left(\mathrm{mcm}^{5} \mathrm{U}\right)$ and further methylated at the ribosyl residue resulting in $\mathrm{mcm}^{5} \mathrm{Um}$, also called Um34 (reviewed in [41]). Um34 formation is increased with increasing selenium [42] and Um34 is responsible for the synthesis of so-called stress-response selenoproteins such as GPx1, GPx3, SelX (MsrB1), SelT, SelH, SelM, SelV, TrxR2, and SelW in murine liver $[43,44]$. The tRNA ${ }^{[\mathrm{ser}] \mathrm{sec}}$ lacking the $2^{\prime}$-methylribose at position $34\left(\mathrm{mcm}^{5} \mathrm{U}\right)$ is responsible for the synthesis of housekeeping selenoproteins (such as TrxR1 and TrxR3) [44]. The observed sensitivity of SelW, GPx1, SelH and SelM to selenium deprivation suggests that the synthesis of these enzymes depends on the tRNA ${ }^{[\mathrm{ser}] \mathrm{sec}}$ methylation in the colon in a similar way as in the liver. An absence or intermediate response to selenium was observed for GPx2, GPx4, SelP, and Sep15, suggesting that their synthesis was partially dependent on Um34 also in the colon. A more complex response was observed for the thioredoxin reductase genes that showed no response by microarray, as expected from their housekeeping function, but a moderate response when assessed by qPCR. The dependency of the remaining selenoproteins (SPS2, SelK, SelS, SelI, Dio1) on Um34 has not been investigated so far.

Contrary to the previous observations of an effect on growth arrest and apoptosis in animals fed various selenium compounds [10-12, 45], no striking effects on these pathways were observed in the present report. This could reflect the fact that substantially higher doses of selenium than here were used in the previous studies. Interestingly, five of the top 15 regulated pathways are involved in protein biosynthesis, indicating a striking effect of selenium on protein biosynthesis in the colon. The net effect of selenium deficiency on protein biosynthesis is not clear since some genes are down-regulated and others up-regulated. However, consistent with this observation, the protein biosynthesis pathway was recently shown to be regulated by selenium supplementation in human lymphocytes too [15]. The comparable findings in two different organs in two different species identify protein synthesis as a pathway that is particularly sensitive to selenium availability. Whether selenoproteins are involved in the regulation of protein synthesis is not known, but SelW [46], SelH [47], and SelM [48] belong to the redoxin family of selenoproteins, which contain a thioredoxin-like fold and a CXXU motif, indicating a redox function. SelW is localized in the cytosol and has been identified as 14-3-3-binding partner [46, 49]. SelH is mainly localized in the nucleoli [47], a site for rRNA biosynthesis and modification [50]. It further has redoxresponsive DNA-binding properties and can regulate genes that respond to changes in the redox status [51]. SelM and SelS/VIMP, for VCP/p97-interacting membrane protein [52], are localized in the endoplasmic reticulum, the site for protein folding and quality control [53]. They might act as chaperones and prevent protein misfolding. A putative redox-regulating capacity of all four above-mentioned selenoproteins influencing translational activity needs further evaluation.

Interestingly, the number of selenium-responsive genes in the Wnt pathway was surprisingly high. Wnt-inhibitory factors and GSK3 $\beta$, were down-regulated, whereas Wnt receptors and the co-receptor (LRP), the stimulatory factors Dvl, $\beta$-catenin and TCF/LEF, as well as $\beta$-catenin targets, the cell type specific differentiation factor pitx2 [54] and c-myc [55], were up-regulated the former at least in qPCR (Fig. 4). By changing the expression of these genes, the predicted net effect of selenium deficiency would be to slightly stimulate the Wnt pathway, hence predisposing the tissue to further Wnt-stimulating agents ultimately leading to carcinogenesis. Recently, Wnt signalling has been linked to the mTOR pathway [56], in which mTOR functions as a central regulator of cell growth [57]. To elucidate whether and how selenium regulates this complex network is a challenging future task.

Selenium deficiency decreased the expression of Smad4 and STAT3 as observed in several cytokine pathways (inflammation) and in the Delta-Notch pathway (carcinogenesis). STATs are activated in response to many different 

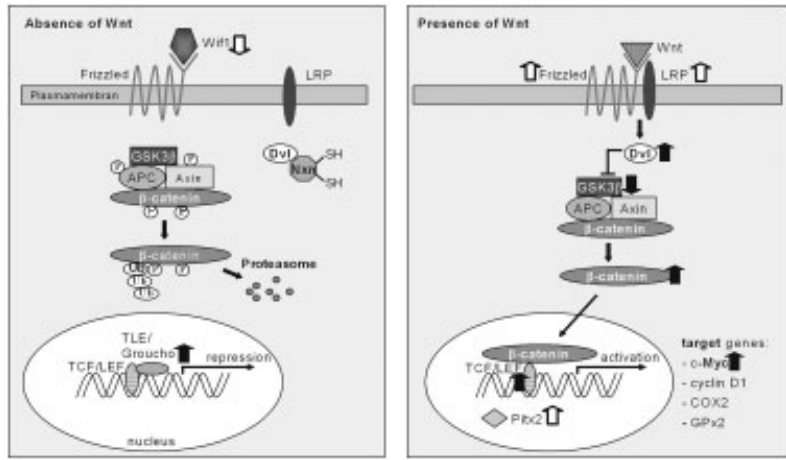

Figure 4. Wnt signalling. (Left side) In the absence of Wnt signals the Wnt receptor frizzled is blocked by, e.g. the Wnt inhibitory factor Wif1 and cytoplasmic $\beta$-catenin is associated in the degradation complex consisting of adenomatous polyposis coli, axin, and glycogen synthase kinase $3 \beta$ (GSK3 $\beta$ ). Phosphorylation of $\beta$-catenin by GSK3 $\beta$ promotes ubiquitinylation (Ub) and subsequent proteasomal degradation of $\beta$-catenin. As a result, levels of free $\beta$-catenin remain low and the formation of the TCF/ LEF(T-cell factor/lymphocyte enhancer factor)- $\beta$-catenin heterodimer in the nucleus is prevented. Instead, TCF/LEF is associated to the transcriptional co-repressor TLE/groucho (transducin-like enhancer of split 2) and acts as a transcriptional repressor. (Right side) Upon binding of Wnt proteins, the Wnt receptor frizzled interacts with its co-receptor LRP (low-density lipoprotein receptor-related protein), resulting in the activation of Dvl which in the silent status is bound to nucleoredoxin $(N \times n)$ and released upon oxidation [58]. Dvl in turn inhibits GSK3 $\beta$. Inactivation of GSK3 $\beta$ prevents phosphorylation and degradation of $\beta$-catenin, which now can translocate into the nucleus where it interacts with TCF/LEF transcription factors and promote expression of specific genes such as c-Myc and Pitx2 [59]. Genes up- and down-regulated by selenium deficiency are indicated by respective arrows. Empty arrows indicate genes found in the PCR array, filled arrows indicate confirmation of microarrays, and/or PCR arrays by real-time PCR.

cytokines and growth factors, whereas Smads transfer TGF $\beta$ signals. TGF $\beta$ is a multifunctional growth factor and has both tumour suppressor and tumour-promoting activities. TGF $\beta$-mediated cell growth is triggered by Smad 2, 3, and 4, which are part of the transcriptional repression complexes, e.g. at the c-myc promoter. Since TGF $\beta$ serves as tumour suppressor in the normal intestinal epithelium, the downregulation of signal transducers such as Smad4 in selenium deficiency might contribute to the generally higher cancer risk in selenium deficiency. How and if, however, selenium interferes with these pathways awaits further investigations.

In conclusion, feeding a marginally selenium-deficient diet to mice led to a change in the global gene expression in the colon. Expression of four selenoproteins (SelW, H, M, and GPx1) dramatically decreased in selenium-deficient status, suggesting that these selenoproteins rank low in the selenoprotein hierarchy in the colon. Interestingly, this correlates with the dependence of synthesis of these selenoproteins on Um34, highlighting the role of this methylated tRNA in the hierarchy. These four selenoproteins should be further investigated as markers for selenium status. Two of them are directly, or indirectly, involved in the regulation of protein folding (SelM, SelW via 14-3-3) and may contribute to the change in genes functioning in protein biosynthesis, which was the pathway most significantly affected by selenium intake. Low selenium intake also modulated cancer-relevant pathways, such as the Wnt, mTOR, and TGF-pathways, and this may contribute to the higher susceptibility to colon carcinogenesis in a seleniumdeficient status.

The authors thank Stefanie Deubel for excellent technical assistance and the team of the animal facilities especially Elke Thom and Swetlana König. The work was supported by two NuGO exchange grants DS 06-013 and PD 06-002 and the German Research Council (DFG), BR 778/8-1. C.M. is supported by NuGO, the EU-funded Network of excellence in Nutrigenomics.

The authors have declared no conflict of interest.

\section{References}

[1] Rayman, M. P., The use of high-selenium yeast to raise selenium status: how does it measure up? Br. J. Nutr. 2004, 92, 557-573.

[2] Rayman, M. P., Selenium in cancer prevention: a review of the evidence and mechanism of action. Proc. Nutr. Soc. 2005, 64, 527-542.

[3] Russo, M. W., Murray, S. C., Wurzelmann, J. I., Woosley, J. T. et al., Plasma selenium levels and the risk of colorectal adenomas. Nutr. Cancer 1997, 28, 125-129.

[4] Jacobs, E. T., Jiang, R., Alberts, D. S., Greenberg, E. R. et al., Selenium and colorectal adenoma: results of a pooled analysis. J. Natl. Cancer Inst. 2004, 96, 1669-1675.

[5] Peters, U., Chatterjee, N., Church, T. R., Mayo, C. et al., High serum selenium and reduced risk of advanced colorectal adenoma in a colorectal cancer early detection program. Cancer Epidemiol. Biomarkers Prev. 2006, 15, 315-320.

[6] Clark, L. C., Combs, G. F., Jr., Turnbull, B. W., Slate, E. H. et al., Effects of selenium supplementation for cancer prevention in patients with carcinoma of the skin. A randomized controlled trial. Nutritional Prevention of Cancer Study Group. J. Am Med. Assoc. 1996, 276, 1957-1963.

[7] Kryukov, G. V., Castellano, S., Novoselov, S. V., Lobanov, A. V. et al., Characterization of mammalian selenoproteomes. Science 2003, 300, 1439-1443.

[8] Wingler, K., Böcher, M., Flohé, L., Kollmus, H. et al., mRNA stability and selenocysteine insertion sequence efficiency rank gastrointestinal glutathione peroxidase high in the hierarchy of selenoproteins. Eur. J. Biochem. 1999, 259, 149-157.

[9] Brigelius-Flohé, R., Tissue-specific functions of individual glutathione peroxidases. Free Radic. Biol. Med. 1999, 27, 951-965. 
[10] Dong, Y., Ganther, H. E., Stewart, C., Ip, C., Identification of molecular targets associated with selenium-induced growth inhibition in human breast cells using cDNA microarrays. Cancer Res. 2002, 62, 708-714.

[11] El-Bayoumy, K., Narayanan, B. A., Desai, D. H., Narayanan, N. K. et al., Elucidation of molecular targets of mammary cancer chemoprevention in the rat by organoselenium compounds using cDNA microarray. Carcinogenesis 2003, 24, 1505-1514.

[12] Rao, L., Puschner, B., Prolla, T. A., Gene expression profiling of low selenium status in the mouse intestine: transcriptional activation of genes linked to DNA damage, cell cycle control and oxidative stress. J. Nutr. 2001, 131, 3175-3181.

[13] Reiter, R., Wendel, A., Selenium and drug metabolism - I. Multiple modulations of mouse liver enzymes. Biochem. Pharmacol. 1983, 32, 3063-3067.

[14] Burk, R. F., Hill, K. E., Nakayama, A., Mostert, V. et al., Selenium deficiency activates mouse liver Nrf2-ARE but vitamin E deficiency does not. Free Radic. Biol. Med. 2008, 44, 1617-1623.

[15] Pagmantidis, V., Meplan, C., van Schothorst, E. M., Keijer, J. et al., Supplementation of healthy volunteers with nutritionally relevant amounts of selenium increases the expression of lymphocyte protein biosynthesis genes. Am. J. Clin. Nutr. 2008, 87, 181-189.

[16] Riese, C., Michaelis, M., Mentrup, B., Gotz, F. et al., Seleniumdependent pre- and posttranscriptional mechanisms are responsible for sexual dimorphic expression of selenoproteins in murine tissues. Endocrinology 2006, 147, 5883-5892.

[17] Ritskes-Hoitinga, M., Nutrition of laboratory mice, in: Hedrich, H. (Ed.), The Laboratory Mouse, Elsevier Acadamic Press, San Diego 2004, pp. 463-479.

[18] van Schothorst, E. M., Pagmantidis, V., de Boer, V. C., Hesketh, J. et al., Assessment of reducing RNA input for Agilent oligo microarrays. Anal. Biochem. 2007, 363, 315-317.

[19] Wettenhall, J. M., Smyth, G. K., limmaGUI: a graphical user interface for linear modeling of microarray data. Bioinformatics 2004, 20, 3705-3706.

[20] Pellis, L., Franssen-van Hal, N. L., Burema, J., Keijer, J., The intraclass correlation coefficient applied for evaluation of data correction, labeling methods, and rectal biopsy sampling in DNA microarray experiments. Physiol. Genomics 2003, 16, 99-106.

[21] Yang, J. J., Yang, M. C., An improved procedure for gene selection from microarray experiments using false discovery rate criterion. Biomed Chromatogr. Bioinform. 2006, 7, 15.

[22] Dahlquist, K. D., Salomonis, N., Vranizan, K., Lawlor, S. C. et al., GenMAPP, a new tool for viewing and analyzing microarray data on biological pathways. Nat. Genet. 2002, 31, 19-20.

[23] Doniger, S. W., Salomonis, N., Dahlquist, K. D., Vranizan, K. et al., MAPPFinder: using Gene Ontology and GenMAPP to create a global gene-expression profile from microarray data. Genome Biol. 2003, 4, R7.

[24] Rodenburg, W., Heidema, A. G., Boer, J. M., BoveeOudenhoven, I. M. et al., A framework to identify physiological responses in microarray-based gene expression studies: selection and interpretation of biologically relevant genes. Physiol. Genomics 2008, 33, 78-90.

[25] Marshall, O. J., PerlPrimer: cross-platform, graphical primer design for standard, bisulphite and real-time PCR. Bioinformatics 2004, 20, 2471-2472.

[26] Vandesompele, J., De Preter, K., Pattyn, F., Poppe, B. et al., Accurate normalization of real-time quantitative RT-PCR data by geometric averaging of multiple internal control genes. Genome Biol. 2002, 3, RESEARCH0034.

[27] Bradford, M. M., A rapid and sensitive method for the quantitation of microgram quantities of protein utilizing the principle of protein-dye binding. Anal. Biochem. 1976, 72, 248-254.

[28] Hrdina, J., Banning, A., Kipp, A., Loh, G. et al., The gastrointestinal microbiota affects the selenium status and selenoprotein expression in mice. J. Nutr. Biochem. 2009, 20, 638-648.

[29] Sheehan, T. M., Gao, M., Simplified fluorometric assay of total selenium in plasma and urine. Clin. Chem. 1990, 36, 2124-2126.

[30] Schomburg, L., Schweizer, U., Holtmann, B., Flohé, L. et al., Gene disruption discloses role of selenoprotein $\mathrm{P}$ in selenium delivery to target tissues. Biochem. J. 2003, 370, 397-402.

[31] Allmang, C., Krol, A., Selenoprotein synthesis: UGA does not end the story. Biochimie 2006, 88, 1561-1571.

[32] National Research Council, Nutrient Requirements of Laboratory Animals, 4th Edn., National Academy Press, Washington, DC 1995.

[33] Shamberger, R. J., Frost, D. V., Possible protective effect of selenium against human cancer. Can. Med. Assoc. J. 1969, 100,682

[34] Duffield-Lillico, A. J., Reid, M. E., Turnbull, B. W., Combs, G. F., Jr. et al., Baseline characteristics and the effect of selenium supplementation on cancer incidence in a randomized clinical trial: a summary report of the Nutritional Prevention of Cancer Trial. Cancer Epidemiol. Biomarkers Prev. 2002, 11, 630-639.

[35] Pagmantidis, V., Bermano, G., Villette, S., Broom, I. et al., Effects of Se-depletion on glutathione peroxidase and selenoprotein $\mathrm{W}$ gene expression in the colon. FEBS Lett. 2005, 579, 792-796.

[36] Hoffmann, P. R., Hoge, S. C., Li, P. A., Hoffmann, F. W. et al., The selenoproteome exhibits widely varying, tissue-specific dependence on selenoprotein $\mathrm{P}$ for selenium supply. Nucleic Acids Res. 2007, 35, 3963-3973.

[37] Yeh, J. Y., Vendeland, S. C., Gu, Q., Butler, J. A. et al., Dietary selenium increases selenoprotein $\mathrm{W}$ levels in rat tissues. J. Nutr. 1997, 127, 2165-2172.

[38] Bermano, G., Arthur, J. R., Hesketh, J. E., Selective control of cytosolic glutathione peroxidase and phospholipid hydroperoxide glutathione peroxidase mRNA stability by selenium supply. FEBS Lett. 1996, 387, 157-160.

[39] Moriarty, P. M., Reddy, C. C., Maquat, L. E., Selenium deficiency reduces the abundance of mRNA for Se-dependent glutathione peroxidase 1 by a UGA-dependent mechanism 
likely to be nonsense codon-mediated decay of cytoplasmic mRNA. Mol. Cell. Biol. 1998, 18, 2932-2939.

[40] Meplan, C., Crosley, L. K., Nicol, F., Beckett, G. J. et al., Genetic polymorphisms in the human selenoprotein $\mathrm{P}$ gene determine the response of selenoprotein markers to selenium supplementation in a gender-specific manner (the SELGEN study). FASEB J. 2007, 21, 3063-3074.

[41] Hatfield, D. L., Carlson, B. A., Xu, X. M., Mix, H. et al., Selenocysteine incorporation machinery and the role of selenoproteins in development and health. Prog. Nucleic Acid Res. Mol. Biol. 2006, 81, 97-142.

[42] Kim, L. K., Matsufuji, T., Matsufuji, S., Carlson, B. A. et al., Methylation of the ribosyl moiety at position 34 of selenocysteine tRNA[Ser]Sec is governed by both primary and tertiary structure. RNA 2000, 6, 1306-1315.

[43] Carlson, B. A., Xu, X. M., Gladyshev, V. N., Hatfield, D. L., Selective rescue of selenoprotein expression in mice lacking a highly specialized methyl group in selenocysteine tRNA. J. Biol. Chem. 2005, 280, 5542-5548.

[44] Carlson, B. A., Moustafa, M. E., Sengupta, A., Schweizer, U. et al., Selective restoration of the selenoprotein population in a mouse hepatocyte selenoproteinless background with different mutant selenocysteine tRNAs lacking Um34. J. Biol. Chem. 2007, 282, 32591-32602.

[45] Dong, Y., Zhang, H., Hawthorn, L., Ganther, H. E. et al., Delineation of the molecular basis for selenium-induced growth arrest in human prostate cancer cells by oligonucleotide array. Cancer Res. 2003, 63, 52-59.

[46] Dikiy, A., Novoselov, S. V., Fomenko, D. E., Sengupta, A. et al., SelT, SelW, SelH, and Rdx12: genomics and molecular insights into the functions of selenoproteins of a novel thioredoxin-like family. Biochemistry 2007, 46, 6871-6882.

[47] Novoselov, S. V., Kryukov, G. V., Xu, X. M., Carlson, B. A. et al., Selenoprotein $\mathrm{H}$ is a nucleolar thioredoxin-like protein with a unique expression pattern. J. Biol. Chem. 2007, 282, 11960-11968.

[48] Ferguson, A. D., Labunskyy, V. M., Fomenko, D. E., Arac, D. et al., NMR structures of the selenoproteins Sep15 and
SelM reveal redox activity of a new thioredoxin-like family. J. Biol. Chem. 2006, 281, 3536-3543.

[49] Aachmann, F. L., Fomenko, D. E., Soragni, A., Gladyshev, V. N. et al., Structural analysis of selenoprotein W and NMR analysis of its interaction with 14-3-3 proteins. J. Biol. Chem. 2007, 282, 37036-37044.

[50] Raska, I., Shaw, P. J., Cmarko, D., Structure and function of the nucleolus in the spotlight. Curr. Opin. Cell Biol. 2006, 18, 325-334.

[51] Panee, J., Stoytcheva, Z. R., Liu, W., Berry, M. J., Selenoprotein $\mathrm{H}$ is a redox-sensing high mobility group family DNA-binding protein that up-regulates genes involved in glutathione synthesis and phase II detoxification. J. Biol. Chem. 2007, 282, 23759-23765.

[52] Ye, Y., Shibata, Y., Yun, C., Ron, D. et al., A membrane protein complex mediates retro-translocation from the ER lumen into the cytosol. Nature 2004, 429, 841-847.

[53] Malhotra, J. D., Kaufman, R. J., Endoplasmic reticulum stress and oxidative stress: a vicious cycle or a doubleedged sword? Antioxid. Redox Signal. 2007, 9, 2277-2293.

[54] Kioussi, C., Briata, P., Baek, S. H., Rose, D. W. et al., Identification of a Wnt/Dvl/beta-Catenin --> Pitx2 pathway mediating cell-type-specific proliferation during development. Cell 2002, 111, 673-685.

[55] He, T. C., Sparks, A. B., Rago, C., Hermeking, H. et al., Identification of c-MYC as a target of the APC pathway. Science 1998, 281, 1509-1512.

[56] Choo, A. Y., Roux, P. P., Blenis, J., Mind the GAP: Wnt steps onto the mTORC1 train. Cell 2006, 126, 834-836.

[57] Schmelzle, T., Hall, M. N., TOR, a central controller of cell growth. Cell 2000, 103, 253-262.

[58] Funato, Y., Michiue, T., Asashima, M., Miki, H., The thioredoxin-related redox-regulating protein nucleoredoxin inhibits Wnt-beta-catenin signalling through dishevelled. Nat. Cell Biol. 2006, 8, 501-508.

[59] van Es, J. H., Barker, N., Clevers, H., You Wnt some, you lose some: oncogenes in the Wnt signaling pathway. Curr. Opin. Genet. Dev. 2003, 13, 28-33. 